\title{
A MULTI-STAGE CASCADE USE OF WOOD COMPOSITE BOARDS
}

\author{
Henrich Lubke, Vladimír Ihnát \\ Slovak Forest Products Research Institute \\ Slovak Republic \\ Vladimír Kuña, Jozef Balberčák \\ Pulp and Paper Research Institute \\ Slovak Republic \\ (Received January 2020)
}

\begin{abstract}
A multi-stage cascade model was implemented on wood composite boards in four stages: particle boards $\rightarrow 100 \%$ recycling $\rightarrow$ middle density fibreboards $\rightarrow 100 \%$ recycling $\rightarrow$ paper liner. Preparation of composite boards bonded with urea-formaldehyde resin was simulated on plates $400 \times 400 \mathrm{~mm}$ and final fiber was pulped using semi-production refiners to create the conditions closed to real. Mass changes and losses were observed during a whole simulated life process.

Results confirmed a deterioration of mechanical strength of recycled particle boards, the flexural strength in $13 \%$ and internal bond strength in $34 \%$ and slight increasing of the modulus of elasticity in static bending in $1.3 \%$. Termomechanical pulping for the fineness in range $13^{\circ} \mathrm{SR}-24^{\circ} \mathrm{SR}$ (Schopper-Riegler) was chosen as appropriate for a fibrous board preparation from recycled chips, but their mechanical properties are at lowest levels compared to the requirements of standards. A low quality paper liner containing OCC, to improve its strength, was produced in the last stage of cascading.
\end{abstract}

KEYWORDS: Multi-stage cascading of wood, particle board, middle density fibre board, recycling, reuse, valorization of wood mass, paper liner.

\section{INTRODUCTION}

Cascading use as the efficient utilization of wood by using residues and material recycling to extend total biomass availability within a given system was executive summarized by European Commission in 2016. As it was concluded cascading at the market level can be quantified through wood flow analysis (Mantau 2015), also within one country (Babuka et al. 2020). A multi-stage 
cascade use is the best option to valorize wood mass. In a single stage cascade, wood product is used once more for energy purposes; in the multi-stage cascading, this product is used at least once more, as materially recovered, before disposal for energy purposes or valorized according to principles of biorefineries (Pažitný et al. 2019).

Different methods can be used to reach this purpose. Reuse of postconsumer wood products (Singh and Ordonez 2016) is the initial point of responsible attitude towards wood resources and waste reduction as well. Combination of methods (reuse and recycling) could be also adapted from pulp and paper industry (Russ et al. 2013), but recycling of waste wood is the most common method applicable in practice (Ihnát et al. 2020). Means of chemical recycling (Balberčák et al. 2017, 2018), as well as means of mechanical disintegration (Ihnát et al. 2017, 2018), are used to obtain clear wood particles for new engineered products. Strong emphasis is being placed on the development of eco-adhesives (Antov et al. 2020, Petar and Savov 2019), both to facilitate recycling and from an environmental point of view, as well.

A wood-based panel and board production sector is one of the most important units in the wood processing industry with the total production of 59,2 million $\mathrm{m}^{3}$ in 2019 according to European Panel Federation. The massive part $\left(32,1 \mathrm{mil} \mathrm{m}^{3}\right)$ of it is formed by a production of particleboards, products with the highest recycle rate. More than one third of sources for their production is coming from recovered wood and this trend is still growing. Utilization of by-products also contribute in cascading (Mirski et al. 2020). The recovered wood is possible to obtain from demolition waste (Sakaguchi et al. 2016, Höglmeier et al. 2017) by simply pre-sorting a pure wood mass. But faster tailor-made identification methods are needed for more detail sorting to get a bigger portion of usable resource and to avoid the contamination of a new production (Faraca 2019). Waste wood pallets, drums and furniture represent a significant resource as well. Recycling of engineered wood may cause technical problems with shredding chips (Laskowska and Maminski 2020) or removal of impurities from recycled chips (Nuryawan et al. 2020), such less valuable wood can be used in the centre layers of new particleboards (Czarnecki et al. 2003).

Recycling of fibrous materials based on wood, as MDF and high density fibreboards (HDF), is connected to untying the bond between wood and cured glue. FT-IR results confirmed that the presence of urea formaldehyde (UF) resin residues on the surface of recycled fibers reasoned for deterioration in properties of recycled MDF boards (Moezzipour et al. 2017). Cured UF resin on the surface of recycled fibers can be also confirmed using SEM and XPS characterizations. For this purpose new processes for aqueous hydrolysis were developed containing weak acids (Lubis et al. 2018). A fiber length of the recycled fibers is shorter and the percentage of shorter fibers is higher for the former and finally, mechanical properties of recycled MDF are lower than those manufactured from a virgin fiber (Zeng et al. 2018). Substitution of other lignocellulosic materials (Ihnát et al. 2015) can significantly improve the total cascade balance for fibrous composite materials based on wood.

The purpose of this study is to demonstrate feasibility of cascading the hardly recoverable composites through an idea to recover wood mass in a sequence from bigger particle to smaller one (fiber). Conversion to "green" chemicals or an extraction of nano-crystalline cellulose (Irle et al. 2019) from waste fiber in the final stage is highly proclaimed, but an incorporation of paper product has been chosen by authors for this research. This incorporation could be a significant step to solve the current insufficient and unsatisfactory disposal capacities of waste MDF (Hagel and Saake 2020). 


\section{MATERIAL AND METHODS}

The multi-stage cascade model of the wood composite boards use has been suggested (Fig. 1) according to the above mentioned definition and primary product (particle board produced of virgin chips) was materially recovered four times.

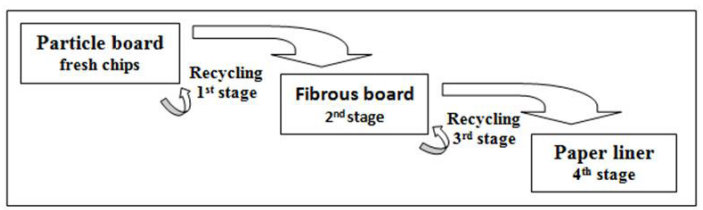

Fig. 1: Scheme of the multi-stage cascade model for a laboratory experiment.

\section{Preparation of a primary particle board (PB) from virgin chips}

Virgin wood chips obtained from a production plant (SK) were used for preparation of primary PB. Mix of softwoods (Populus) and hardwoods (mainly Fagus sylvatica and Carpinus betulus) was used in the ratio 1:1. The fraction of chips was determined by sieving (Tab. 1). The chips $0.2 \mathrm{~mm}-2 \mathrm{~mm}$ and $2 \mathrm{~mm}-4 \mathrm{~mm}$ were used for a surface and core of PB, resp.

Tab. 1: The fraction composition of chips used for the preparation of primary $P B$.

\begin{tabular}{|c|c|c|}
\hline \multicolumn{3}{|c|}{ Comparative sample (stage 0) } \\
\hline Sieve (mm) & Surface chips (\%) & Core chips (\%) \\
\hline 8 & - & 1.2 \\
\hline 4 & - & 34.7 \\
\hline 2 & 1.29 & 33.7 \\
\hline 1 & 16.17 & 23.1 \\
\hline 0.2 & 58.05 & 5.6 \\
\hline Residue & 24.49 & 1.7 \\
\hline
\end{tabular}

An adhesive mixture was applied to dried wood chips with moisture content of $5 \%$ in an adhesive applicator (Defibrator, SE). The adhesive mixture was composed of the urea-formaldehyde adhesive (UF) - Kronores CB $1100 \mathrm{~F}$ with addition of the 5\% hardener DAM 390. A paraffin emulsion in the amount of $0.8 \%$ paraffin on the dry matter of chips in form of a $30 \%$ emulsion was added. The surface and middle chips are in a ratio of 1:1. Individual components of the adhesive mixture are equally represented for surface and center chips. The moisture content of chips in the matt before its compressing was $14.8 \%$ after application of the adhesive mixture. The formed chips matt was pressed in a press at temperature of $180^{\circ} \mathrm{C}$ for $230 \mathrm{sec}$. The resulted board was then formatted and air-conditioned.

\section{Recycling of the particle board}

The primary particle board disintegration

The initial destruction of primary $\mathrm{PB}$ was performed by size reduction to pieces about $10 \times 10 \mathrm{~cm}$. The pieces were cooked for $30 \mathrm{~min}$ to uptake their content of moisture. To disintegrate them, a drum chipper Pallmann equipped with longitudinal slits (length $54.1 \mathrm{~mm}$, width $5.5 \mathrm{~mm}$ ) was used. Chips were dried at $105^{\circ} \mathrm{C}$ and sieved. The fraction of chips prepared in the drum chipper was determined by sieving (Tab. 2). 


\section{The recycled particle board preparation}

Recycled PB was prepared from 100\% chips obtained from primary PB without adding of virgin chips. The same procedure, as the above mentioned, was used for applying the adhesive mixture. The adhesive mixture was composed of Kronores CB $1100 \mathrm{~F}$ with $5 \%$ hardener DAM 390. An amount of $0.8 \%$ paraffin on chips in form of $30 \%$ emulsion was added. The surface and middle chips are in a ratio of 1:1. The formed chips matt was pressed at temperature of $180^{\circ} \mathrm{C}$ for $230 \mathrm{sec}$. The resulted board was then formatted and air-conditioned.

\section{Determination of mechanical properties}

Mechanical properties of $\mathrm{PB}$ prepared from virgin chips, also recycled $\mathrm{PB}$, were determined according to EN 310 (1993) (flexural strength and flexural modulus) and EN 319 (1995) (tensile strength perpendicular to the board- Internal bond). Properties were determined on Heckert FTZ 10/1. All mechanical properties were determined after boards' conditioning at $20^{\circ} \mathrm{C}$ and $45 \%$ humidity.

\section{Preparation of a fiber board from the recycled particleboard}

\section{The recycled $P B$ disintegration}

Chips were prepared from recycled $\mathrm{PB}$, disintegrated to pieces $10 \mathrm{x} 10 \mathrm{~cm}$ for 30 , which were boiling in water for $30 \mathrm{~min}$ to achieve a min $40 \%$ moisture content (Ihnat et al 2017). The drum chipper Palmann with oval openings $(5.5 \mathrm{~mm}, 54.1 \mathrm{~mm}$ ) was used to prepare the chips. Distribution of the prepared chips was determined by laboratory sieving after drying at $105^{\circ} \mathrm{C}$ (Tab. 2). For fiber preparation, chips smaller than $2 \mathrm{~mm}$ were removed.

Tab. 2: The fraction composition of chips prepared from the 30 min cooking of primary/recycled PB bonded with UF resin, which were chipped on the drum chipper Pallman.

\begin{tabular}{|c|c|c|}
\hline Cascading & (stage 1) & (stage 2) \\
\hline Sieve (mm) & chips from primary PB (\%) & chips from recycled PB (\%) \\
\hline 8 & - & 12.4 \\
\hline 4 & 19,3 & 30.3 \\
\hline 2 & 20,3 & 15.4 \\
\hline 1 & 20,7 & 22.4 \\
\hline 0,2 & 25,6 & 17.6 \\
\hline Residue & 14,1 & 1.9 \\
\hline
\end{tabular}

Wood fiber preparation from chips obtained from recycled $P B$

Chips above $2 \mathrm{~mm}$ were heated to $80^{\circ} \mathrm{C}$ in water before grinding to achieve $\min 40 \%$ of the moisture content. A disc refiner Sprout-Waldron was also heated to this temperature. The chips were ground in a single pass through the grinding heads of the device. The obtained fiber with a fineness of grinding $5^{\circ} \mathrm{SR}$ (Schopper-Riegler) was insufficient for the needs of preparation of fibreboards. So the fiber was refined on Valley holander gradually 18, 40, 50,70 min with increasing degree of ${ }^{\circ} \mathrm{SR}$ to $13,24,28,40$, resp.

\section{$M D F$ preparation from fiber obtained from recycled $P B$}

A board with a thickness of $16 \mathrm{~mm}$ was made from the prepared fiber. An adhesive mixture was applied to a dried wood fiber with a relative humidity of $5 \%$ in an adhesive applicator (Defibrator, SE). The adhesive mixture was composed of urea-formaldehyde adhesive (UF) Kronores CB $1100 \mathrm{~F}$ with the addition of 5\% hardener DAM 390. It may contain a paraffin 
emulsion in the amount of $0.8 \%$ paraffin on the dry matter of chips in the form of a $30 \%$ emulsion. The amount of $13 \%$ of adhesive mixture on the dry matter of the chips was used. After application of the adhesive mixture, the relative humidity of fiber in the mat before the carpet is being compressed was $16.3 \%$. The formed fibrous mat was pressed at temperature of $180^{\circ} \mathrm{C}$ for $250 \mathrm{sec}$. The board was then formatted and air-conditioned.

\section{Recycling of the MDF}

Wood fiber preparation from $M D F$ bonded with UF resin

The MDF was cut into $10 \times 10 \mathrm{~cm}$ sections. These were boiled in water at atmospheric pressure with constant stirring for $3 \mathrm{~min}$, until they reached a relative moisture content of at least $40 \%$. The swollen parts of MDF were milled (one pass through) on the disc refiner SproutWaldron at temperature $\min 80^{\circ} \mathrm{C}$.

\section{A recycled $M D F$ preparation}

A board with a thickness of $16 \mathrm{~mm}$ was made from the recycled fiber under the same as the above mentioned conditions. The adhesive mixture was composed of Kronores CB $1100 \mathrm{~F}$ with 5\% hardener DAM 390. The paraffin emulsion was added as well. The amount of $13 \%$ of adhesive mixture on the dry matter of the chips was used. The formed fibrous mat was pressed at temperature of $180^{\circ} \mathrm{C}$ for $250 \mathrm{sec}$. The board was then formatted and air-conditioned.

\section{Preparation of a paper liner from recycled MDF Pulp preparation}

The recycled MDF was disintegrated to fiber by boiling in water, as mentioned above, and milled on the Sprout -Waldron under the same conditions. An amount of old corrugated cardboards (OCC), pulped in water (ratio 1:1) was added to a water mixture of wood fiber at $80^{\circ} \mathrm{C}$. After mixing the components, the pulp was ground on a cone mill Jylha 0 . The fiber produced was characterized by fractionation on Brecht-Holl fractionator. The fiber, pulp and mixture as well, was characterized by a dewatering time, amount of water retained (WRV), Schopper-Riegler grade ( $\left.{ }^{\circ} \mathrm{SR}\right)$ and defibrator grades (DS) (Tab. 3).

\section{Paper liner preparation}

The laboratory handsheets $\left(160 \mathrm{~g} \cdot \mathrm{m}^{-2}\right)$ were prepared on a Rapid Köthen sheet former according to ISO 5269-2 (2004). Samples were tested for an tensile index ISO 1924-2 (2008), tear index ISO 1974 (2012), burst index ISO 2758 (2001), air permeation resistance - Gurley method (ISO 5636-5 2003) for the determination of basic mechanical properties Tappi methods were used for determination of tensile strength $(\mathrm{kPa})$, tensile energy absorption $\left(\mathrm{J} \cdot \mathrm{m}^{-2}\right)$, and tear strength $(\mathrm{m} \cdot \mathrm{N})$.

Tab. 3: Pulp properties.

\begin{tabular}{|c|c|c|c|c|}
\hline \multicolumn{2}{|l|}{ Cascading } & & (stage 3) & \\
\hline \multicolumn{2}{|l|}{ Sample } & $\mathrm{OCC}$ & Wood fiber DS- 38 & Mixture (1:1) \\
\hline \multicolumn{2}{|c|}{ Schopper-Riegler ( $\left.{ }^{\circ} \mathrm{SR}\right)$} & 50 & 13 & 37 \\
\hline \multirow{4}{*}{$\begin{array}{l}\text { Dewatering time } \\
\text { (sec.) }\end{array}$} & $500 \mathrm{ml}$ & 40.91 & 6.0 & 22.0 \\
\hline & $700 \mathrm{ml}$ & 95.41 & 13.8 & 59.5 \\
\hline & $800 \mathrm{ml}$ & 142.62 & 23.27 & 92.3 \\
\hline & chips & 0 & 7.76 & 0 \\
\hline
\end{tabular}




\begin{tabular}{|l|c|c|c|c|}
\hline \multirow{3}{*}{ Brecht-Holl } & 16 & 37.375 & 52.41 & 45.3 \\
\cline { 2 - 5 } & 50 & 22.330 & 19.47 & 20.92 \\
\cline { 2 - 5 } & 100 & 6.410 & 5.41 & 9.57 \\
\cline { 2 - 5 } & -100 & 33.885 & 12.95 & 24.21 \\
\hline WRV (\%) & & 130.9 & 95.7 & 114.8 \\
\hline
\end{tabular}

\section{RESULTS AND DISCUSSION}

The model of a multi-stage cascade use of composite panels was laboratory implemented and evaluated on the every single stage as follow:

\section{Preparation of the primary $\mathrm{PB}$ and recycled $\mathrm{PB}$}

Mechanical properties of prepared PB were determined according to EN 310 (1993): Wood based panels. Determination of modulus of elasticity in bending and of bending strength and EN 319 (1993): Particleboards and fibreboards. Determination of tensile strength perpendicular to the plane of the board. Final properties are showed in Tab. 4. The last column shows values required by EN 312-3 (2016): Particleboards. Specifications. Part 3: Requirements for boards for interior fitments (including furniture) for use in dry conditions.

Tab. 4: Properties of PB.

\begin{tabular}{|c|c|c|c|c|}
\hline \multirow{2}{*}{\multicolumn{2}{|c|}{ Cascading }} & (stage 0$)$ & (stage 1) & \\
\hline & & Primary PB & Recycled PB & $\begin{array}{c}\text { Standard } \\
\text { (requirements EN 312-3) }\end{array}$ \\
\hline \multicolumn{2}{|l|}{ Density $\left(\mathrm{kg} \cdot \mathrm{m}^{-3}\right)$} & 650 & 650 & - \\
\hline \multicolumn{2}{|c|}{ Flexural strength $\left(\mathrm{N} \cdot \mathrm{mm}^{-2}\right)$} & 21.51 & 18.79 & 13 \\
\hline \multicolumn{2}{|c|}{ Modulus of elasticity $\left(\mathrm{N} \cdot \mathrm{mm}^{-2}\right)$} & 2291 & 2321 & 1600 \\
\hline \multicolumn{2}{|c|}{ Internal bond $\left(\mathrm{N} \cdot \mathrm{mm}^{-2}\right)$} & 1.07 & 0.71 & 0.35 \\
\hline \multirow{2}{*}{ Thickness swelling } & 2 hod (\%) & 3.05 & 3.01 & 5 \\
\hline & 24 hod (\%) & 7.87 & 6.98 & 10 \\
\hline
\end{tabular}

As expected the recycling process caused deterioration of the main mechanical properties of PB. The flexural (bending) strength has been reduced from $21.51 \mathrm{~N} \cdot \mathrm{mm}^{-2}$ to $18.79 \mathrm{~N} \cdot \mathrm{mm}^{-2}$ and the internal bond (perpendicular to the plane of the board) strength from $1.07 \mathrm{~N} \cdot \mathrm{mm}^{-2}$ to $0.71 \mathrm{~N} \cdot \mathrm{mm}^{-2}$. The reduction represents $13 \%$, and $34 \%$, resp. But on the other side, the modulus of elasticity in static bending increased from $2291 \mathrm{~N} \cdot \mathrm{mm}^{-2}$ to $2321 \mathrm{~N} \cdot \mathrm{mm}^{-2}$ which represents the increment of $1.3 \%$. Similar results achieved Lykidis and Grigoriou (2008) after hydrothermal recovering the particles under a low pressure and temperature $119^{\circ} \mathrm{C}$. They also found that after the second hydrothermal recycling under pressure $\left(8 \mathrm{bars}, 167^{\circ} \mathrm{C}, 20 \mathrm{~min}\right)$ the modulus of elasticity has been increased by $20.7 \%$. It is evident that chips during a hydrothermal treatment, which is needed to separate them from each other, pass to the higher elastic stage depending on the strength and duration of the treatment. A higher elasticity may cause reduction of long-term deflections of boards in service. 


\section{Preparation of a fiber board from recycled $\mathrm{PB}$}

The composition of chips from recycled PB (Tab. 2) has a high proportion of fine chips below $2 \mathrm{~mm}$, so the amount of usable chips for fiber preparation represents only $58.1 \%$ (sieve 2,4 , and 8). The obtained fiber with a grinding fineness of $5^{\circ} \mathrm{SR}$ is insufficient for preparation of MDF (Tab. 5), due to the high proportion of fiber 16 (40 mesh) in comparison with fibers from the boiled MDF (comparative sample). Therefore, refining on Valley holander gradually 18, 40, 50, 70 min with increasing degree ${ }^{\circ} \mathrm{SR} 13,24,28,40$ was provided.

Tab. 5: Distribution and properties of fiber from waste PB after the 30 min cooking and grinding on the Sprout-Waldron mill and additional refining on the Valley-holander.

\begin{tabular}{|c|c|c|c|c|c|c|c|}
\hline \multicolumn{2}{|c|}{ Cascading } & \multicolumn{5}{|c|}{ (stage2) } & \multirow[b]{2}{*}{$\begin{array}{l}\text { Comparative } \\
\text { sample MDF }\end{array}$} \\
\hline \multicolumn{2}{|c|}{ Method of fiber preparation } & $\begin{array}{l}\text { Sprout- } \\
\text { Waldron } \\
\text { milling }\end{array}$ & \multicolumn{4}{|c|}{$\begin{array}{c}\text { Sprout-Waldron and Valley holander } \\
\text { refinering }\end{array}$} & \\
\hline \multicolumn{2}{|c|}{${ }^{\circ} \mathrm{SR}$} & 5 & 13 & 24 & 28 & 40 & 10 \\
\hline \multicolumn{2}{|c|}{ Milling time } & - & $18 \mathrm{~min}$ & $40 \mathrm{~min}$ & $50 \mathrm{~min}$ & $70 \mathrm{~min}$ & - \\
\hline \multirow{3}{*}{$\begin{array}{l}\text { Dewatering } \\
\quad(\text { sec.) }\end{array}$} & $500 \mathrm{ml}$ & 1.66 & 2.47 & 12.46 & 14.25 & 19.47 & 2.25 \\
\hline & $700 \mathrm{ml}$ & 2.60 & 4.70 & 21.38 & 26.73 & 49.19 & 3.05 \\
\hline & $800 \mathrm{ml}$ & 3.02 & 9.50 & 28.00 & 38.66 & 74.92 & 3.35 \\
\hline \multirow{5}{*}{$\begin{array}{c}\text { Brecht-Holl } \\
\text { (\%) }\end{array}$} & Chips & 0 & 0 & 0 & 0 & 0 & 4.243 \\
\hline & 16 (mesh 40) & 67.18 & 42.52 & 25.90 & 20.15 & 4.175 & 47.207 \\
\hline & $50($ mesh 120$)$ & 18.82 & 40.56 & 47.48 & 48.04 & 49.330 & 24.295 \\
\hline & $100($ mesh 240$)$ & 10.76 & 10.13 & 13.47 & 16.12 & 19.490 & 15.970 \\
\hline & $+100($ mesh 240$)$ & 3.23 & 6.79 & 13.15 & 15.73 & 26.805 & 8.285 \\
\hline
\end{tabular}

The fiber distribution (Tab. 5) shows a good agreement in the amount of rough fiber 16 (40 mesh) and a higher value of the middle fine fiber $50(120 \mathrm{mesh})$ at $13^{\circ} \mathrm{SR}$. Fine fiber fractions are in a good agreement as well. The content of $4.2 \%$ of chips of the comparative MDF indicates it's not completed decomposition. At $24^{\circ} \mathrm{SR}$ (grinding for $40 \mathrm{~min}$ ), the major part of fibers is shifted from rough to medium finesses. The percentage of fine fibers is in a good agreement with the comparative sample. The shift of the fiber distribution is also evident by the dewatering (retention) time, which increases with the decrease of the fine fibers fraction. This implies the possibility of grinding the chips into fibers in the range of $13^{\circ} \mathrm{SR}-24^{\circ} \mathrm{SR}$ for the production of $\mathrm{MDF}$ from recovered chips. The fiber $28^{\circ} \mathrm{SR}-40^{\circ} \mathrm{SR}$ would require more adhesive to prepare $\mathrm{MDF}$, as it contains more dust particles. Termomechanical pulp from recycling boards are of shorter fibre length and higher content of fine fraction (Roffael et al. 2010). Boards prepared from fiber with $13^{\circ} \mathrm{SR}$ have the properties as showed in Tab. 7 (stage 2).

\section{Recycling of MDF}

The fiber obtained after grinding on the disc refiner Sprout-Waldron by one pass through the device was characterized by a dewatering rate and the Brecht-Holl fractionation. The obtained parameters are in a good agreement with the comparative MDF. The obtained fiber is sufficient without a further processing to prepare new MDF. 
Tab. 6: Distribution and properties of fiber from waste MDF after 3 min of cooking and grinding (one pass trough) on a disc refiner Sprout-Waldron.

\begin{tabular}{|l|l|c|c|}
\hline Cascading & & (stage 3) & \\
\hline $\begin{array}{l}\text { Method of fiber } \\
\text { preparation }\end{array}$ & & $\begin{array}{c}\text { Sprout-Waldron } \\
\text { milling }\end{array}$ & $\begin{array}{c}\text { Comparative sample } \\
\text { (MDF) }\end{array}$ \\
\hline${ }^{\circ}$ SR & $\mathbf{1 2}$ & $\mathbf{1 0}$ \\
\hline \multirow{4}{*}{ Dewatering (sec.) } & $500 \mathrm{ml}$ & 2.12 & 2.25 \\
\cline { 2 - 4 } & $700 \mathrm{ml}$ & 6.21 & 3.05 \\
\cline { 2 - 4 } & $800 \mathrm{ml}$ & 10.18 & 3.35 \\
\hline \multirow{4}{*}{ Brecht-Holl (\%) } & Chips & 0 & 4.243 \\
\cline { 2 - 4 } & $16($ mesh 40) & 42.11 & 47.207 \\
\cline { 2 - 4 } & $50($ mesh 120) & 34.78 & 24.295 \\
\cline { 2 - 4 } & $100($ mesh 240) & 12.13 & 15.970 \\
\cline { 2 - 4 } & $+100($ mesh 240) & 10.98 & 8.285 \\
\hline
\end{tabular}

After weekly conditioning at $20^{\circ} \mathrm{C}$ and $\mathrm{HC} 45 \%$, the properties of prepared MDF are listed in Tab. 7. The table also contains the required values according to STN EN 622-5 (2010): Fibreboards. Requirements for dry board (MDF). Flexural strength and flexural modulus of elasticity were determined according to EN 310 (1993), and tensile strength perpendicular to the plane according to EN 319 (1995).

Tab. 7: Properties of fibre boards.

\begin{tabular}{|c|c|c|c|c|}
\hline \multirow{2}{*}{\multicolumn{2}{|c|}{ Cascading }} & (stage 2) & (stage 3) & \\
\hline & & MDF & Recycled MDF & $\begin{array}{c}\text { Standard (min. value) } \\
\text { STN EN 622-5 }\end{array}$ \\
\hline \multicolumn{2}{|l|}{ Density $\left(\mathrm{kg} \cdot \mathrm{m}^{-3}\right)$} & 720 & 720 & - \\
\hline \multicolumn{2}{|c|}{ Flexural strength $\left(\mathrm{N} \cdot \mathrm{mm}^{-2}\right)$} & 22.15 & 21,98 & 20 \\
\hline \multicolumn{2}{|c|}{ Modulus of elasticity $\left(\mathrm{N} \cdot \mathrm{mm}^{-2}\right)$} & 2284 & 2208 & 2200 \\
\hline \multicolumn{2}{|c|}{ Internal bond $\left(\mathrm{N} \cdot \mathrm{mm}^{-2}\right)$} & 1.12 & 1.03 & 0.55 \\
\hline \multirow{2}{*}{ Thickness swelling } & $2 \operatorname{hod}(\%)$ & 3.05 & 4.45 & 5 \\
\hline & 24 hod (\%) & 7.87 & 9.8 & 10 \\
\hline
\end{tabular}

The flexural strength of fully recycled MDF (stage 3) has been reduced from $22.15 \mathrm{~N} \cdot \mathrm{mm}^{-2}$ to $21.98 \mathrm{~N} \cdot \mathrm{mm}^{-2}$, modulus elasticity from $2284 \mathrm{~N} \cdot \mathrm{mm}^{-2}$ to $2208 \mathrm{~N} \cdot \mathrm{mm}^{-2}$ and internal bond strength from $1.12 \mathrm{~N} \cdot \mathrm{mm}^{-2}$ to $1.03 \mathrm{~N} \cdot \mathrm{mm}^{-2}$. These reductions represent up to $8 \%$ only, but the mechanical properties of MDF (stage 2) produced from fibers obtained from recycled chips are on a bottom level comparing to standard requirements (Tab. 7). Roffael et al. (2010) stated that termomechanical pulp obtained from recycling boards can be used up to $30 \%$ as a partial substitute for pulp from wood in making UF-bonded MDF without any noteworthy deterioration of the physical-mechanical board properties.

\section{Preparation of paper liner from recycled MDF}

The strength properties were determined on the laboratory prepared handsheets $\varnothing 220 \mathrm{~mm}$ (Tab. 8). Mechanical properties of paper liner made of termomechanical pulp obtained from recycled wood composites and mixed with OCC are lower as from semichemical pulp obtained from the same material (Balberčák et al. 2017). Additional treatment can significantly improve their mechanical properties, also their resistance to oil and grease (Gigac et al. 2018). 
Tab. 8: Properties of the paper liner.

\begin{tabular}{|l|c|c|}
\hline \multicolumn{1}{|c|}{ Cascading } & (Pažitný et al. 2013) & (stage 4) \\
\hline Basic weight $\left(\mathrm{g} \cdot \mathrm{m}^{-2}\right)$ & - & 164 \\
\hline Thickness $(\mu \mathrm{m})$ & 129 & 459 \\
\hline Bulk density $\left(\mathrm{cm}^{3} \cdot \mathrm{g}^{-1}\right)$ & - & 0.36 \\
\hline Tensile index $\left(\mathrm{N} \cdot \mathrm{m}^{-} \mathrm{g}^{-1}\right)$ & $36-93.25$ & 33.2 \\
\hline Burst strength $(\mathrm{kPa})$ & 160 & 156 \\
\hline Burst index $\left(\mathrm{kPa} \cdot \mathrm{m}^{2} \cdot \mathrm{g}^{-1}\right)$ & $2-5.85$ & 1.8 \\
\hline Air permeation resistance $(\mathrm{Gurley}$ method) $(\mathrm{s})$ & $9.3-22.34$ & 6.1 \\
\hline Tensile energy absorption $\left(\mathrm{J} \cdot \mathrm{m}^{-2}\right)$ & 43 & 74 \\
\hline Tear strength $(\mathrm{m} \cdot \mathrm{N})$ & 485 & 620 \\
\hline Tear index $\left(\mathrm{m} \cdot \mathrm{N} \cdot \mathrm{m}^{2} \cdot \mathrm{g}^{-1}\right)$ & $4.4-6.10$ & 5.6 \\
\hline
\end{tabular}

Pažitný et al. (2013) have reached similar values for liners made from energetic grasses mixed with OCC. The strength properties of the liner prepared in this study are lower compared to the properties of the wrapping paper, but the paper is consistent and is more suitable for the practical use in higher basis weights, e.g. as pads, underlay bases, paper for separating the layers of material/goods from each other etc.

\section{CONCLUSIONS}

The cascading use of wood takes place in many forms. Recycling as the most usable form of material recovery is hardly realizable for wood based composites. To realize its full potential, barriers to cascading need to be overcome. Fiber shortening, glue residual stickled to wood particles and deterioration of mechanical properties are accompanying features of the recycling process. This article presents one way of a multi-stage cascade model for wood composite boards bonded with UF resin, where the principle of recycling "the bigger sized particle to smaller" was applied. The results confirmed a well-know knowledge that the mechanical properties of recycled products are lower than that from virgin wood. The last stages of cascading in this material flow showed that properties are at the lowest levels of properties required by valid standards. Hydrothermal recovery of particles and termomechanical pulping are important processes in a valorization process of wood mass but at the cost of reduced mechanical properties. Low cost paper liner could be a solution for the final stages of cascading of glued wood based composites, but wider research is needed.

\section{ACKNOWLEDGMENTS}

This research was supported by the Slovak Research and Development Agency under the contract No. APVV-17-0330. 


\section{REFERENCES}

1. Antov, P., Savov, V., 2019: Possibilities for manufacturing eco-friendly medium density fibreboards from recycled fibres. A Review. In: 30th International Conference on Wood Science and Technology "Implementation of wood science in woodworking sector" and $70^{\text {th }}$ anniversary of Drvna industrija Journal, $7 \mathrm{pp}$.

2. Antov, P., Savov, V., Neykov, N., 2020: Sustainable bio-based adhesives for eco-friendly wood composites. A review. Wood Research 65(1): 51-62.

3. Babuka, R., Sujová, A., Kupčák, V., 2020: Cascade use of wood in the Czech Republic. Forests 11: 681.

4. Balbercak, J., Bohacek, S., Medo, P., Ihnat, V., Lubke, H., 2017: Chemical processing of waste wood based agglomerates Part I: Evaluation of properties of fluting liners made of semichemical pulp obtained by a mildly alkaline sulphur-free cooking process. Wood Research 62(5): 715-726.

5. Balbercak, J., Bohacek, S., Pazitny, A., Ihnat, V., Lubke, H., 2018: Chemical processing of waste wood based agglomerates part II: Evaluation of properties of fluting liners made of semichemical pulp obtained by an alkaline cooking process. Wood Research 63(1): 35-44.

6. Czarnecki, R., Dziurka, D., Lecka, J., 2003: The use of recycled boards as the substitute for particleboard in the centre layer of particleboards. Electronic Journal of Polish Agricultural Universities. Wood Technology 6(2) (published online).

7. Faraca, G., Boldrin, A., Astrup, T., 2019: Resource quality of wood waste: The importance of physical and chemical impurities in wood waste for recycling. Waste Management 87(15): 135-147.

8. Gigac, J., Stankovská, M., Fišerová, M., 2018: Improvement of oil and grease resistance of cellulosic materials. Wood Research 63(6): 871-886.

9. Hagel, S., Saake, B., 2020: Fractionation of waste MDF by steam refining. Molecules 25: 2165 .

10. Höglmeier, K., Weber-Blaschke, G., Richter, K., 2017: Potentials for cascading of recovered wood from building deconstruction. A case study for south-east Germany. Resources, Conservation and Recycling 117 (Part B): 304-314.

11. Ihnat, V., Boruvka, V., Lubke, H., Babiak, M., Schwartz, J., 2015: Straw pulp as a secondary lignocellulosic raw material and its impact on properties of properties of insulating fiberboards. Part III. Preparation of insulating fiberboards from separately milled lignocellulosic raw materials. Wood Research 60(3): 457-466.

12. Ihnat, V., Lubke, H., Boruvka, V., Russ, A., 2017: Waste agglomerated wood materials as a secondary raw material for chipboards and fibreboards. Part I: Preparation and characterization of wood chips in term of their reuse. Wood Research 62(1): 45-56.

13. Ihnát, V., Lübke, H., Russ, A., Pažitný, A., Borůvka, V., 2018: Waste agglomerated wood materials as a secondary raw material for chipboards and fibreboards. Part II: Preparation and characterization of wood fibres in terms of their reuse. Wood Research 63(3): 431-442.

14. Ihnát, V., Lübke, H., Balberčák, J., Kuňa, V., 2020: Size reduction downcycling of waste wood. Review. Wood Research 65(2): 205-220.

15. Irle, M., Privat, F., Couret, L., Belloncle, Ch., Déroubaix, G., Bonnin, E., Cathala, B., 2019: Advanced recycling of post-consumer solid wood and MDF. Wood Material Science \& Engineering 14(1): 19-23.

16. Laskowska, A., Maminski, M., 2020: The properties of particles produced from waste plywood by shredding in a single-shaft shredder. Maderas. Ciencia y tecnología 22(2) (online). 
17. Lubis, M.A.R., Hong, M.K., Park, B.D., 2018: Hydrolytic removal of cured ureaformaldehyde resins in medium-density fiberboard for recycling. Journal of Wood Chemistry and Technology 38(1): 1-14.

18. Lykidis, Ch., Grigoriou, A., 2008: Hydrothermal recycling of waste and performance of the recycled wooden particleboards. Waste management 218(1): 57-63.

19. Mantau, U., 2015: Wood flow analysis: Quantification of resource potentials, cascades and carbon effects. Biomass and Bioenergy 79: 28-38.

20. Mirski, R., Dukarska, D., Derkowski, A., Czarnecki, R., Dziurka, D., 2020: By-products of sawmill industry as raw materials for manufacture of chip-sawdust boards. Journal of Building Engineering 32: 101460.

21. Moezzipour, B., Ahmadi, M., Abdolkhani, A., Doosthoseini, K.,2017: Chemical changes of wood fibers after hydrothermal recycling of MDF wastes. Journal of Indian Academy of Wood Science 14: 133-138.

22. Nuryawan, A., Rahmawaty, Tambun, K.D.S., Risnasari, I., Masruchin, N., 2020: Hydrolysis of particleboard bonded with urea-formaldehyde resin for recycling. Heliyon 6(5): e03936.

23. Pažitný, A., Russ, A., Boháček, Š., Bottová, V., Černá, K., 2013: Utilization of energetic grass for modification of recovered fibre properties. Wood Research 58 (2): 181-190.

24. Pažitný, A., Russ, A., Boháček, Š., Stankovská, M., Ihnát, V., Šutý, Š., 2019: Various lignocellulosic raw materials pretreatment processes utilizable for increasing holocellulose accessibility for hydrolytic enzymes. Part II. Effect of steam explosion temperature on beech enzymatic hydrolysis. Wood Research 64(3): 437-448.

25. Roffael, E., Dix, B., Behn, C., Bär, G., 2010: Use of UF-bonded recycling particle-and fibreboards in MDF-production. European Journal of Wood Products 68: 121-128.

26. Russ, A., Schwartz, J., Boháček, Š., Lübke, H., Ihnat, V., Pažitný, A., 2013: Reuse of old corrugated cardboard in constructional and thermal insulating boards. Wood Research 58(3): 505-510.

27. Sakaguchi, D., Takano, A., Hughes, M., 2016: The potential for cascading wood from demolished buildings: the condition of recovered wood through a case study in Finland. International Wood Products Journal 7(3): 137-143.

28. Singh, J., Ordonez, I., 2016: Resource recovery from post-consumer waste: important lessons for the upcoming circular economy. Journal of Cleaner Production134: 342-353.

29. Zeng, Q., Lu, Q. Zhou, Y., Chen, N., Rao, J., Fan, M., 2018: Circular development of recycled natural fibers from medium density fiberboard wastes. Journal of Cleaner Production 202(20): 456-464.

\author{
Henrich Lubke*, Vladimír Ihnát \\ Slovak Forest Products Research Institute \\ Dúbravská Cesta i4 \\ 84I o4 Bratislava \\ Slovak Republic \\ *Corresponding author: lubke.sdvu@vupc.sk
}


Vladimír Kuña, Jozef BalberčÁk

Pulp and Paper Research Institute

Dúbravská Cesta i4

84I O4 Bratislava

Slovak Republic 